\title{
Association between Tooth Size Discrepancies and Angle Malocclusions in a Tunisian Sample \\ Hassouna Elyes ${ }^{1 *}$, Dallel Ines ${ }^{2}$, Saadi Nada ${ }^{1}$, Tobji Samir ${ }^{2}$, Ben Amor Adel ${ }^{2}$
}

${ }^{1}$ Resident in Dento-Facial Orthopedics at the Monastir Dental Clinic, Monastir University, Tunisia

${ }^{2}$ Professor in Dento-Facial Orthopedics at the Monastir Dental Clinic, Monastir University, Tunisia

DOI: $10.36347 /$ sjds.2021.v08i01.008

| Received: 26.12.2020 | Accepted: 03.01.2021 | Published: 23.01.2021

*Corresponding author: Hassouna Elyes

Abstract

Original Research Article

Objective: The objective of this study was to investigate the frequency and to compare the overall and anterior ratios of tooth size discrepancies in all Angle malocclusions groups. Materials and methods: The mesio-distal tooth width and arch width were measured on a total of 120 orthodontic 3D models of Tunisian patients aged between 18-37 years of different occlusal relationships (Class I, Class II division 1 Class II division 2 and Class III malocclusions). The overall and anterior ratios between the maxillary and mandibular teeth were evaluated using Bolton's method. The following statistical tests were applied: independent t-test, and one-way ANOVA. Results: Women presented smaller teeth than men, which mainly concern the first molar in the maxilla, the canine, the second premolar and the first molar in the mandible. The anterior ratio was $78.59 \% \pm 2.47$, with $78.93 \% \pm 2.41$ for men and $78.26 \% \pm 2.54$ for women and the overall ratio was $91.69 \% \pm 1.41$ with $92.21 \% \pm 1.30$ for men and $91.16 \% \pm 2.37$ for women. There was no relationship between anterior and overall ratio and gender or malocclusion groups. Conclusion: This work showed the presence of sexual dimorphism concerning tooth size. Our comparison of the TSD results with those noted by Bolton, showed anterior and overall ratios that are slightly higher than his standard values. Therefore, the original Bolton's values should be used conservatively in Tunisian population. No differences in the overall and anterior ratios of tooth size discrepancies were found among Angle malocclusion groups and gender.

Keywords: Tooth size; Bolton ratio; Tooth size discrepancy; malocclusion.

Copyright (C) 2021 The Author(s): This is an open-access article distributed under the terms of the Creative Commons Attribution 4.0 International License (CC BY-NC 4.0) which permits unrestricted use, distribution, and reproduction in any medium for non-commercial use provided the original author and source are credited.

\section{INTRODUCTION}

A proper balance should exist between the mesiodistal tooth size of the maxillary and mandibular arches to ensure proper intercuspdation, overbite, and overjet at the end of orthodontic treatment. The purpose of the final phase of orthodontic treatment is to make the occlusion perfect, both functionally and aesthetically [1]. In many cases, the finishing phase is difficult and time consuming [2]. Lots of these difficulties are related to the tooth size discrepancies between upper and lower dentition [2, 3]. After the introduction of the "six essential keys of normal occlusion" by Andrews in 1972 [4], further studies [5] put importance on the "seventh key" which was the "tooth size".

Furthermore, difference in tooth size have been associated with different ethnic backgrounds and also with different malocclusions [6, 7], influenced by genetic [8, 9] and environmental factors [10] and various studies have investigated ethnic and sex differences in the intermaxillary tooth ratios. Bolton's ratio is one of the most commonly used methods to determine inter-arch tooth size discrepancy in orthodontic patients and has been widely used in scientific studies since its publication [11, 12]. However, due to the selection bias in Bolton's study (subjects with an excellent occlusion were selected for his study, while population and gender characteristics of the study sample were unspecified), Bolton's ratio may differ in the subjects with malocclusions and in different population groups [13-16].

Considering that there are very few studies that focused on the association between Bolton discrepancy and Angle malocclusions, and the available literature is inconsistent. Therefore, the purpose of this study was to compare the overall and anterior Bolton ratios among different malocclusion groups using a sample from the Tunisian population. 


\section{MATERIALS AND METHODS}

A total of 120 sets of 3D models were obtained from patients (age range 18-37 years), who consulted the Dentofacial Othopedics Department of the Monastir Dental Clinic, including the different malocclusions groups (Class I, Class II division 1, Class II division 2, and Class III malocclusions). The distribution of subjects according to sex and malocclusion group is shown in Table-1.

Table-1: Distribution of Subjects According to Sex and Malocclusion Group

\begin{tabular}{|l|l|l|l|l|l|}
\hline \multirow{2}{*}{ Gender } & Angle class & \multirow{2}{*}{ Total } \\
\cline { 2 - 6 } & Class I & Class II div1 & Class II div2 & Class III & 60 \\
\hline Number of males & 21 & 10 & 9 & 20 & 60 \\
\hline Number of females & 19 & 11 & 10 & 20 & 60 \\
\hline Total & 40 & 21 & 19 & 40 & 120 \\
\hline
\end{tabular}

The inclusion criteria for the subjects were as follow:

1. Complete permanent dentition with no caries, proximal restorations, attrition, or dental anomalies.

2. All teeth fully erupted to the occlusal plan.

3. No previous or ongoing orthodontic treatment.

4. No transverse discrepancies such as cross bite or scissors bite.

5. Tunisian origin

The mesio-distal tooth width from first molar to first molar was obtained on the orthodontic 3D models by measuring the greatest distance between the contact points on proximal surfaces using the software Inlab SW version 19.

These measurements were performed by the same operator and were compared to measurements made with a digital caliper with an accuracy of 0.01 $\mathrm{mm}$ on 15 randomly selected upper and lower casts; any difference greater than $0.5 \mathrm{~mm}$ was considered clinically significant [16]. The result of this comparison showed a negligible difference, of the order of 0.02 to $0.2 \mathrm{~mm}$, which confirms the reliability of the software used in this study.

The method proposed by Bolton [10] was adopted for calculation of tooth size discrepancy:
Anterior ratio $(\mathrm{AR})=[($ Sum of mesio-distal width of mandibular six anterior teeth)/ (Sum of mesio-distal width of maxillary six anterior teeth) $] \times 100 \%$

Overall ratio $(\mathrm{OR})=[($ Sum of mesiodistal width of mandibular 12 teeth)/ (Sum of mesiodistal width of maxillary 12 teeth)] $\times 100 \%$

\section{STATISTICAL ANALYSIS}

The statistical analysis was performed using IBM SPSS version 23.0 software and the significance level was set at $\mathrm{p}<0.05(5 \%)$. The t-test of independent samples was used to compare mesiodistal tooth width and TSD between men and women and the ANOVA test was used to compare the overall and ratio between the different groups of malocclusions.

\section{RESULTS}

\section{Female to Male Comparisons Tooth Size}

The comparison of the tooth size between men and women showed the presence of sexual dimorphism.

In the maxilla, the first molar was significantly wider in men $(\mathrm{p}<0.001)$. In the mandible, the canine $(p<0.01)$, second premolar $(p<0.001)$ and first molar $(\mathrm{p}<0.001)$ were significantly less wide in women (Table-2).

Table-2: Permanent tooth widths in Tunisian adults

\begin{tabular}{|c|c|c|c|c|c|c|c|}
\hline \multirow[t]{2}{*}{ Tooth } & \multicolumn{2}{|l|}{ Men } & \multicolumn{2}{|c|}{ Women } & \multicolumn{2}{|l|}{ Total } & \multirow[t]{2}{*}{$\mathrm{p}$} \\
\hline & Mean & SD & Mean & SD & Mean & SD & \\
\hline \multicolumn{8}{|c|}{ Maxillary } \\
\hline \multirow{6}{*}{$\begin{array}{l}\mathrm{I} 1 \\
\mathrm{I} 2 \\
\mathrm{C} \\
\mathrm{P} 1 \\
\mathrm{P} 2 \\
\mathrm{M}\end{array}$} & 8.74 & 0.66 & 8.70 & 0,49 & 8.72 & 0.51 & 0.18 \\
\hline & 6.98 & 0.50 & 6.90 & 0,43 & 6.94 & 0.47 & 0.25 \\
\hline & 7.82 & 0.35 & 7.70 & 0,33 & 7.76 & 0.34 & 0.16 \\
\hline & 7.05 & 0.22 & 6.95 & 0,31 & 7 & 0.27 & 0.33 \\
\hline & 6.87 & 0.28 & 6.78 & 0,25 & 6.82 & 0.24 & 0.09 \\
\hline & 10.42 & 0.43 & 10.04 & 0,50 & 10.23 & 0.44 & $0.0007 * * *$ \\
\hline \multicolumn{8}{|c|}{ Mandibular } \\
\hline \multirow{6}{*}{$\begin{array}{l}\text { I1 } \\
\text { I2 } \\
\text { C } \\
\text { P1 } \\
\text { P2 } \\
\text { M }\end{array}$} & 5.52 & 0.44 & 5.45 & 0,41 & 5.48 & 0.42 & 0.08 \\
\hline & 6.05 & 0.44 & 6.03 & 0,40 & 6.04 & 0.42 & 0.07 \\
\hline & 7.01 & 0.46 & 6.74 & 0,38 & 6.87 & 0.42 & $0.004 * *$ \\
\hline & 7.25 & 0.35 & 7.07 & 0,43 & 7.16 & 0.37 & 0.06 \\
\hline & 7.42 & 0.42 & 7.13 & 0,42 & 7.27 & 0.35 & $0.0009 * * *$ \\
\hline & 11.19 & 0.59 & 10.78 & 0,57 & 10.98 & 0.58 & $0.0002 * * *$ \\
\hline
\end{tabular}

I1, Central incisor; I2, lateral incisor; C, canine; P1, first premolar; P2, second premolar; M, first molar; SD, Standard deviation; * p $<0,05 ; * * \mathrm{p}<0,01 ; * * * \mathrm{p}<0,001$. 


\section{Tooth size discrepancies (TSD)}

The anterior and overall ratios, according to the formulas published by Bolton were calculated and the resulting data were pooled in Table-3.

Our results showed that the anterior ratio was $78.59 \% \pm 2.47$, with $78.93 \% \pm 2.41$ for men and
$78.26 \% \pm 2.54$ for women. The overall ratio was $91.69 \% \pm 1.41$ with $92.21 \% \pm 1.30$ for men and $91.16 \%$ \pm 2.37 for women.

The t-test of the independent samples, used to compare the TSD between men and women, showed that this difference is not significant.

Table-3: Mean Ratios of Bolton Anterior and Overall Analysis as a Function of Sex

\begin{tabular}{|l|l|l|l|l|l|}
\hline Gender & & Number & Mean (\%) & SD & p \\
\hline \multirow{3}{*}{ Men } & AR & 60 & 78.93 & 1.41 & 0.15 \\
\cline { 2 - 6 } & OR & 60 & 92.21 & 1.30 & 0.09 \\
\hline \multirow{3}{*}{ Tomen } & AR & 60 & 78.26 & 1.54 & 0.25 \\
\cline { 2 - 5 } & OR & 60 & 91.16 & 1.37 & 0.08 \\
\hline & AR & 120 & 78.59 & 1.47 & \\
\cline { 2 - 5 } & OR & 120 & 91.69 & 1.41 & \\
\hline
\end{tabular}

AR: Anterior ratio; OR: Overall Ratio; SD: Standard deviation

\section{Comparisons between the different malocclusion groups}

The results obtained from the comparison of the overall and ratio between the different groups of malocclusions, using the ANOVA test, are summarized in Table-4. The descriptive analyses showed that the means were significantly similar and the difference obtained is not significant.

Table-4: Mean Ratios of Bolton Anterior and Overall Analysis as a Function of Angle Class

\begin{tabular}{|c|c|c|c|c|c|}
\hline \multicolumn{2}{|c|}{ Angle Class/Bolton Ratio } & Number & Mean (\%) & SD & $\mathbf{p}$ \\
\hline \multirow[t]{2}{*}{ Class I } & AR & 40 & 78.06 & 1.57 & 0.08 \\
\hline & OR & 40 & 91.87 & 1.61 & 0.14 \\
\hline \multirow[t]{2}{*}{ Class II div 1} & AR & 21 & 78.76 & 1.23 & 0.16 \\
\hline & OR & 21 & 90.28 & 1.23 & 0.28 \\
\hline \multirow[t]{2}{*}{ Class II div 2} & AR & 19 & 78.54 & 1.55 & 0.33 \\
\hline & OR & 19 & 90.62 & 1.71 & 0.89 \\
\hline \multirow[t]{2}{*}{ Class III } & AR & 40 & 79.07 & 1.47 & 0.25 \\
\hline & OR & 40 & 92.74 & 1.19 & 0.09 \\
\hline \multirow[t]{2}{*}{ Total } & AR & 120 & 78.59 & 1.47 & \\
\hline & OR & 120 & 91.69 & 1.41 & \\
\hline
\end{tabular}

AR: Anterior ratio; OR: Overall Ratio; SD: Standard deviation;

\section{DISCUSSION}

Given that tooth size discrepancies may be influenced by malocclusion type, ethnicity and sex, the mesio-distal tooth width and the TSD was compared in relation to the different types of malocclusions of Class I, Class II division 1, Class II division 2 and Class III and according to the gender of 120 patients who consulted the Monastir Dentofacial Orthopedics Department.

Although diagnostic measurements have traditionally been based on plaster dental casts, with the advancement of 3D digital imaging technology, emodels are a valid alternative [17] Moreover, digital measurement is more rapid and less variable than the manual method.

The size of the teeth of the Tunisian population remains comparable to that of the teeth of individuals from Morocco and Saudi Arabia. However, this size remains smaller than those measured on melanoderms and relatively larger than those noted on Caucasians.

Studies of Hispanic populations, in particular, have shown that there is a significant difference in tooth size compared to Caucasians, but it is similar to that found in African-Americans.

According to Lavelle [18], the average mesiodistal crown diameter is larger in melanoderms than in Caucasians and Mongoloids are intermediate.

These variations are attributed to environmental, genetic, dietary and ethnic factors [19, 20, 21].

Similarly, we found that there is a significant difference in tooth size between men and women, shown in this study, which confirms the presence of sexual dimorphism. Thus, we observed that men have teeth larger than the opposite sex, which mainly 
concern the first molar in the maxilla, and the canine, second premolar and first molar in the mandible. This is consistent with the results obtained in other studies in different populations [18, 22]. A Chinese study [23] found that females had statistically significant $(\mathrm{p}<$ 0.05 ) smaller teeth than males with the exception of the upper left and right lateral incisors, lower left lateral incisor, and lower left and right central incisors.

Bishara [24] found that canines and molars were significantly larger in boys than in girls, and he found no significant differences between incisors in three different populations (Mexico, Egypt and Iowa).

Several studies [9] have suggested that this sexual dimorphism is mainly related to Y-chromosome stimulation of growth [25, 26], while other researchers have suggested that hormonal influences during tooth development are also important.

In our study, the result of the measurement of the Bolton ratio, as a function of sex, showed that the AR was $78.59 \% \pm 1.47$, with $78.93 \% \pm 1.41$ for men and $78.26 \% \pm 1.54$ for women and the OR having an average of $91.69 \% \pm 1.41$, with $92.21 \% \pm 1.30$ for men and $91.16 \% \pm 1.37$ for women, these differences remain insignificant. This is in agreement with majority of previously reported findings [27-30], but contrasting findings have been reported by other studies [20,31].

Our comparison of the TSD results with those noted by Bolton, showed an AR and OR that were slightly higher than his standard values $(77.2 \% \pm 1.65$ for RA and $91.3 \% \pm 1.91$ for RG). This difference was to be expected since his standards are not applicable to all individuals. This inconsistency would be linked to criticism of this ratio, since, first of all, estimates of Bolton's ratio were underestimated because his sample was derived from patients with a perfect Class I occlusion. Similarly, the population and sex composition of Bolton's sample was not specified, which constitutes a potential selection bias.

Smith et al., [20] mentioned that the parameters considered normal for Bolton's ratio cannot be applied only to white women and that there are significant differences in anterior and overall ratio between Whites, Blacks and Hispanics.

A review of the literature by Othman and Harradine [32] stated that Bolton's ratio is probably not a good indicator of the prevalence and diagnosis of the tooth size discrepancy and cannot be applicable to all populations. Therefore, it can be concluded that the Bolton index differs from one population to another, and even within the same population.

In this study, the comparison of the Bolton ratio according to the different malocclusions did not reveal any significant difference, which is in agreement with other studies carried out on other ethnic groups: studies by Crosby and Alexander [6] on a sample of 109 patients divided into four malocclusion groups (class I, class II division 1, class II division 2 and surgical class II), not including Angle's class III subject, did not show a statistically significant difference in the incidence of TSD between these four occlusion categories. Similarly, studies by Uysal et al., [33] in 2005 on 150 patients with class I and 560 patients with the other malocclusion + groups (class I, class II division 1, class II division 2 and Angle class III) did not show statistically significant differences between the different classes of malocclusion. Similar findings have been reported from Japanese [34] and Moroccan [35] studies conducted in 2008 and 2014, respectively, stating that the TSD is not related to dental class. Akyalcin et al., [36] found that in a skeletally similar sample of 152 subjects, no statistically significant differences were determined for the Bolton anterior and overall tooth size prevalence and means among the Angle Class I, II, and III groups and sex also was not discriminating.

However, several studies have affirmed the presence of a correlation between TSD and malocclusions. Lavelle showed that Bolton's ratios will be greater in class III subjects than in other occlusion classes, which is in agreement with the work of Nie and Lin [29].

Studies carried out on different populations in Brazil Araujo and Souki [2], Turkey Oktay [37], Ireland O'Mahony [38] and Poland and Croatia WedrychowskaSzulc B [39] have revealed a relationship between the TSD and the incidence of malocclusion.

These observations suggest that there is a divergence of opinion among the authors regarding the incidence of TSD in malocclusions among different ethnic groups and thus remains a controversial issue that may be the source of future research in this subject.

\section{CONCLUSION}

- This work showed the presence of sexual dimorphism concerning tooth size. In fact, women presented smaller teeth than men, which mainly concern the first molar in the maxilla, the canine, the second premolar and the first molar in the mandible. On the other hand, this difference is not systematic and does not interest all teeth.

- Our comparison of the TSD results with those noted by Bolton, showed anterior and overall ratios that are slightly higher than his standard values. Therefore, the original Bolton's values should be used conservatively in Tunisian population.

- No differences in the overall and anterior ratios of tooth size discrepancies were found among Angle malocclusion groups and gender. 
Conflict of Interest statement: All authors declare that we have no conflict of interest of this work.

\section{REFERENCES}

1. Fourquet L, Göttle M, Bounoure G. Finishing and detailing, stability and harmony. L'Orthodontie francaise. 2014 Mar 1;85(1):93-125.

2. Araujo E, Souki M. Bolton anterior tooth size discrepancies among different malocclusion groups. The Angle Orthodontist. 2003 Jun;73(3):307-13.

3. Ebadifar A, Taliee R. Comparison of Bolton's ratios before and after treatment in an Iranian population. J Dent Res Dent Clin Dent Pro-spects. 2013; 7(1):30-5.

4. Andrews L. The six keys to normal occlusion. Am J Orthod. 1972; 62(3):296-309.

5. Maurya R, Gupta A, Garg J, Mishra HA. Seventh key of occlusion: diagnostic significance in different angle's class I, II and III malocclusions. J Orthod Res. 2015; 3(3):188.

6. Crosby DR, Alexander CG. The occurrence of tooth size discrepancies among different malocclusion groups. Am J Orthod Dentofacial Orthop. 1989; 95:457-61.

7. Lavelle CL. Maxillary and mandibular tooth size in different racial groups and in different occlusal categories. Am J Orthod. 1992; 61:29-37

8. Dempsey PA, Townsend GC. Genetic and environmental contributions to variation in human tooth size. Heredity. 2001 Jun;86(6):685-93.

9. Townsend G, Bockmann M, Hughes T, Brook A. Genetic, environmental and epigenetic influences on variation in human tooth number, size and shape. Odontology. 2012; 100:1-9.

10. Alam M, Hassan R, Mahmood Z, Haq M. Determination and comparison of tooth size and tooth size ration in normal occlusion and different malocclusion groups. Int Med J. 2013; 20:462-5.

11. Bolton WA. Disharmony in tooth size and its relation to the analysis and treatment of malocclusion. Angle Orthod.1958; 28:113-130.

12. Bolton WA. The clinical application of tooth-size analysis. Am J Orthod. 1962;48:504-529.

13. Smith SS, Buschang PH, Watanabe E. Interarch tooth size relationships of 3 populations: "Does Bolton's analysis apply?". American Journal of Orthodontics and Dentofacial Orthopedics. 2000 Feb 1;117(2):169-74.

14. Johe RS, Steinhart T, Sado N, Greenberg B, Jing S. Intermaxillary tooth-size discrepancies in different sexes, malocclusion groups, and ethnicities. American journal of orthodontics and dentofacial orthopedics. 2010 Nov 1;138(5):599607.

15. Ricci ID, Scanavini MA, Kaieda AK, Rosário HD, Paranhos LR. Bolton ratio in subjects with normal occlusion and malocclusion. Brazilian Journal of Oral Sciences. 2013 Dec;12(4):357-61.
16. O'Mahony G, Millett DT, Barry MK, McIntyre GT, Cronin MS. Tooth size discrepancies in Irish orthodontic patients among different malocclusion groups. The Angle Orthodontist. 2011 Jan $1 ; 81(1): 130-3$.

17. El-Zanaty HM, El-Beialy AR, Abou El-Ezz AM, Attia KH, El-Bialy AR, Mostafa YA. Threedimensional dental measurements: an alternative to plaster models. American Journal of Orthodontics and Dentofacial Orthopedics. 2010 Feb 1;137(2):259-65.

18. Lavelle CL. Maxillary and mandibular tooth size in different racial groups and in different occlusal categories. Am J Orthod. 1992; 61:29-37.

19. Ribeiro DC, Brook AH, Hughes TE, Sampson WJ, Townsend GC. Intrauterine hormone effects on tooth dimensions. J Dent Res. 2013; 92:425-31.

20. Smith SS, Buschang PH, Watanabe E. Interarch tooth size relationships of 3 populations: "Does Bolton's analysis apply?". Am J Orthod Dentofacial Orthop. 2000;117:169-74.

21. Ballard ML. Asymmetry in tooth size: a factor in the etiology, diagnosis and treatment of malocclusion. Angle Orthod. 1984; 14:67-70.

22. Arya BS, Sayara BS, Thomas D, Clarkson Q. Relation of sex and occlusion to mesiodistal tooth size. Am J Orthod. 1994; 66:479-86.

23. Leung EM, Yang Y, Khambay B, Wong RW, McGrath C, Gu M. A Comparative Analysis of Tooth Size Discrepancy between Male and Female Subjects Presenting with a Class I Malocclusion. The Scientific World Journal. 2018 Jan 1;2018.

24. Bishara SE, Jakobsen JR, Abdallah EM, Fernandez Garcia A. Comparisons of mesiodistal and buccolingual crown dimensions of the permanent teeth in three populations from Egypt, Mexico, and the United States. Am J Orthod Dentofacial Orthop 1989; 96:416-22.

25. Guatelli- Steinberg D, Sciulli PW, Betsinger TK. Dental crown size and sex hormone concentrations: another look at the development of sexual dimorphism. American Journal of Physical Anthropology: The Official Publication of the American Association of Physical Anthropologists. 2008 Nov;137(3):324-33.

26. Alvesalo L. Human sex chromosomes in oral and craniofacial growth. Arch Oral Biol. 2009; 54:S18-24.

27. Al-Khateeb SN, Abu Alhaija ES. Tooth size discrepancies and arch parameters among different malocclusions in a Jordanian sample. The Angle Orthodontist. 2006 May;76(3):459-65.

28. Hashim HA, Najah AS, Hashim AH. Bolton tooth size ratio among qatari population sample: An odontometric study. Journal of orthodontic science. 2017 Jan;6(1):22.

29. Nie Q, Lin J. Comparison of intermaxillary tooth size discrepancies among different malocclusion groups. American Journal of Orthodontics and 
Dentofacial Orthopedics. 1999 Nov 1;116(5):53944.

30. Basaran G, Selek M, Hamamcı O, Akkuş Z. Intermaxillary Bolton tooth size discrepancies among different malocclusion groups. The Angle Orthodontist. 2006 Jan;76(1):26-30.

31. Mollabashi V, Soltani MK, Moslemian N, Akhlaghian M, Akbarzadeh M, Samavat H, Abolvardi M. Comparison of Bolton ratio in normal occlusion and different malocclusion groups in Iranian population. International orthodontics. 2019 Mar 1;17(1):143-50.

32. Othman SA, Harradine NW. Tooth-size discrepancy and Bolton's ratios: a literature review. J Orthod. 2006; 33:45-51.

33. Uysal T, Sari Z, Basciftci FA, Memili B. Intermaxillary tooth size discrepancy and malocclusion: is there a relation? Angle Orthod. 2005; 75:208-13.

34. Endo T, Abe R, Kuroki H, Oka K, Shimooka S. Tooth size discrepancies among different malocclusions in a Japanese orthodontic population. Angle Orthod. 2008; 78:994-9.

35. Zerouaoui MF, Bahije L, Zaoui F, Regragui S. Etude des variations de l'indice de Bolton en fonction des malocclusions d'angle dans la population marocaine. Int Orthod. 2014; 12:21321.

36. Akyalçin S, Doğan S, Dinçer B, Erdinc AM, Oncağ G. Bolton tooth size discrepancies in skeletal Class I individuals presenting with different dental angle classifications. Angle Orthod. 2006; 76(4):637-43.

37. Oktay H, Ulukaya E. Intermaxillary tooth size discrepancies among different malocclusion groups. Eur J Orthod. 2010; 32:307-12.

38. O'Mahony G, Millett DT, Barry MK, Mclntyre GT, Cronin MS. Tooth size discrepancies in Irish orthodontic patients among different malocclusion groups. Angle Orthod. 2011; 81:130-3.

39. Wedrychowska-Szulc B, Janiszewska-Olszowska J, Stepień P. Overall and anterior Bolton ratio in Class I, II, and III orthodontic patients. Eur J Orthod. 2010; 32:313-8. 